\title{
Rutaecarpine alleviates renal ischemia reperfusion injury in rats by suppressing the JNK/p38 MAPK signaling pathway and interfering with the oxidative stress response
}

\author{
CHUNHUA WANG $^{1}$, ZONGYAO HAO $^{2}$, JUN ZHOU ${ }^{2}$, LI ZHANG ${ }^{2}$, YEXIANG SUN ${ }^{1}$ and CHAOZHAO LIANG ${ }^{2}$ \\ Departments of ${ }^{1}$ Burns and ${ }^{2}$ Urology, The First Affiliated Hospital of Anhui \\ Medical University, Hefei, Anhui 230032, P.R. China
}

Received April 25, 2016; Accepted March 23, 2017

DOI: $10.3892 / \mathrm{mmr} .2017 .6631$

\begin{abstract}
In the present study, the protective effect and the potential underlying mechanism of rutaecarpine $(\mathrm{Ru})$ on renal ischemia reperfusion injury (IRI) in rats were investigated. A renal ischemia reperfusion mouse model was established. $\mathrm{Ru}$ at $30,60 \mathrm{mg} / \mathrm{kg}$ administered intraperitoneally prior to reperfusion led to attenuated renal injury. The results demonstrated that $\mathrm{Ru}$ treatment significantly reduced the content of serum creatinine, urea nitrogen and neutrophil gelatinase-associated lipocalin in rats with renal IRI. In addition, $\mathrm{Ru}$ treatment improved the degree of renal proximal tubular necrosis, decreased the content of inflammatory cytokines in reperfused renal tissue and increased serum superoxide dismutase levels to protect the kidney. The associated underlying mechanism may involve the inhibition of p38 kinase phosphorylation and c-Jun N-terminal kinase, anti-lipid peroxidation, elimination of free radicals, and a reduction in the degree of apoptotic damage and oxidative stress injury induced by renal IRI. Therefore, Ru may be a suitable compound for the prevention and treatment of renal IRI.
\end{abstract}

\section{Introduction}

In the late 1970s, Wasser et al (1) first observed that renal injury became more severe following renal ischemia reperfusion, thus, the concept of renal ischemia reperfusion injury (IRI) was introduced (1). The kidney, which is a hypertransfusion organ, is more sensitive to ischemia and ischemia reperfusion than other organs. The incidence of renal ischemia reperfusion worldwide is $\sim 13-38 \%$, of which $\sim 80 \%$ is induced by acute renal tubular injury (2-4). Renal IRI is commonly observed in

Correspondence to: Professor Chaozhao Liang, Department of Urology, The First Affiliated Hospital of Anhui Medical University, 81 Meishan Road, Hefei, Anhui 230032, P.R. China

E-mail: ahmulcc@163.com

Key words: rutaecarpine, ischemia reperfusion injury, inhibition, p38, c-Jun N-terminal kinase, oxidative stress clinical settings, including during kidney transplantation, renal vascular surgery, extracorporeal lithotripsy and shock resuscitation. Renal IRI is a severe injury, which results in acute ischemic renal failure. It often induces delayed graft function and upregulates the expression of major histocompatibility complex (MHC) I and MHC II antigens, thereby aggravating immunological rejection and leading to serious graft function loss (5-7).

Inflammation serves an important role in the occurrence and progression of renal IRI. Previous studies have demonstrated that neutrophil infiltration in the reperfused renal tissue, and the levels of tumor necrosis factor (TNF)- $\alpha$, transforming growth factor- $\beta$, interleukin (IL)- 6 , IL- $1 \beta$, inflammatory cytokines, monocyte chemoattractant protein, IL- 8 and normal $\mathrm{T}$ cells, secretory factors and other chemotactic factors increase in IRI (8-10). Reactive oxygen species (ROS) are also produced in large quantities under these conditions. High concentrations of ROS induce apoptosis and necrosis through the cell oxidative stress response. Therefore, inhibiting the inflammatory signaling pathway and the production of inflammatory mediators may effectively reduce kidney damage (11-13). The mitogen-activated protein kinase (MAPK) pathway is known as the cellular survival pathway. The MAPK pathway in mammalian cells is involved in a number of processes affecting the final cellular response, including cell proliferation, differentiation and adaptation to environmental stress and apoptosis (14). The c-Jun N-terminal kinase (JNK)/p38 MAPK signaling pathway, a subclass of MAPKs, is active in a number of tissues and cells, and serves an important role in mediating inflammatory reactions. Previous studies have demonstrated that the JNK/p38 MAPK signaling pathway is activated in cells following IRI $(15,16)$. Inflammatory cytokines, including nuclear factor $(\mathrm{NF})-\kappa \mathrm{B}$, intercellular adhesion molecule (ICAM)-1, TNF- $\alpha$ and IL-6, also activate this pathway $(17,18)$. Thus, blocking the JNK/p38 MAPK signaling pathway and inhibiting the production of ROS may effectively alleviate early organ dysfunction following renal IRI.

Evodia rutaecarpa, was originally recorded in 'Shen Nong's Herbal Classic' (19), and is classified as a traditional interior-warming herb and a medium-grade drug in traditional Chinese medicine. The herb is pungent, bitter, heated and slightly poisonous. In traditional Chinese medicine, it 
is believed to affect the liver, spleen, stomach and kidney channels and is commonly used to treat hypertension, and gastrointestinal and gynecological diseases. Rutaecarpine $(\mathrm{Ru})$, a quinazoline carboline alkaloid, is one of the main components of E. rutaecarpa (Fig. 1) (20). Ru exhibits significant anti-inflammatory and immunomodulatory effects. Previous studies have investigated the pharmacological activity of this substance and have demonstrated its multiple-targeting effects (21-23). Ru appears to inhibit secretion of inflammatory mediators, release of ROS, expression of adhesion molecules, activation and infiltration of neutrophils, as well as generally regulate immunity (21-23). At present, to the best of our knowledge, there is no information available on the ability of $\mathrm{Ru}$ to reduce multiple-organ IRI. Therefore, the effect and underlying mechanism of $\mathrm{Ru}$ on early-stage renal IRI were investigated using a rat renal IRI model. The influence of $\mathrm{Ru}$ on inflammatory mediators, the JNK/p38 MAPK signaling pathway and the oxidative stress response were also investigated. The present results may provide information about the potential use of $\mathrm{Ru}$ as a new drug to treat organ IRI.

\section{Materials and methods}

Materials. A total of 50 adult male Sprague-Dawley rats (age, 6-8 weeks; weight, $250 \pm 10 \mathrm{~g}$ ) were obtained from the Institute of Laboratory Animal Sciences, Anhui Medical University (Hefei, China). All the animals were housed in individual cages with a constant temperature $\left(18-20^{\circ} \mathrm{C}\right)$ and humidity $(65-69 \%)$ at $12 / 12 \mathrm{~h} \mathrm{light/dark}$ cycle with free access to food and water. All experimental procedures were approved by the Animal Experimental Ethics Committee of Anhui Medical University (Hefei, China). Ru was obtained from the School of Pharmaceutical Sciences, Sun Yat-sen University (Guangzhou, China). The nuclear magnetic resonance (NMR) analysis results for Ru were as follows: ${ }^{1} \mathrm{H}$ NMR (500 MHz, d6-DMSO): $\delta 3.21(\mathrm{t}$, $J=7.0 \mathrm{~Hz}, 2 \mathrm{H}), 4.44(\mathrm{t}, J=7.0 \mathrm{~Hz}, 2 \mathrm{H}), 7.12(\mathrm{dt}, J=7.5,1.0 \mathrm{~Hz}$, $1 \mathrm{H}), 7.27$ (dt, $J=7.5,1.0 \mathrm{~Hz}, 1 \mathrm{H}), 7.47-7.51(\mathrm{~m}, 2 \mathrm{H}), 7.62$ (d, $J=8.5 \mathrm{~Hz}, 1 \mathrm{H}), 7.70$ (d, $J=7.5 \mathrm{~Hz}, 1 \mathrm{H}), 7.78-7.84$ (m, 1H), 8.18 $(\mathrm{dd}, J=8.0,1.0 \mathrm{~Hz}, 1 \mathrm{H}), 11.88(\mathrm{~s}, 1 \mathrm{H}) ;{ }^{13} \mathrm{C} \mathrm{NMR}(125 \mathrm{MHz}$, d6-DMSO): $160.5,146.9,145.2,138.8,134.7,127.0,126.4$, $126.3,126.2,124.8,124.6,120.5,120.1,119.6,117.8,112.5$, 40.9, 18.7; HRMS calcd for $\mathrm{C}_{18} \mathrm{H}_{13} \mathrm{~N}_{3} \mathrm{O}$ 287.1059; Found: 287.1064. Enzyme-linked immunosorbent assay (ELISA) kits for NF- $\kappa$ B (cat. no. H202), ICAM-1 (cat. no. KF066), TNF- $\alpha$ (cat. no. H052) and IL-6 (cat. no. H007) were purchased from Bioval Technologies (Shanghai, China). Superoxide dismutase activity (SOD; cat. no. A001-1) and lipid peroxidation malondialdehyde (MDA; cat. no. A003-1) assay kits were purchased from Nanjing Jian Cheng Bioengineering Research Institute (Nanjing, China).

Experimental design. The IRI rat model was established by superior mesenteric artery (SMA) occlusion, as described previously (24). Rats were anesthetized with chloral hydrate (100 mg/kg) intraperitoneally and randomly divided into the following five groups ( $n=10 /$ group): Sham group (sham operation; isolation of the SMA without occlusion), normal saline (NS) group (a group treated with $10 \mathrm{ml} / \mathrm{kg}$ saline 10 min prior reperfusion); IRI group (intestinal ischemia reperfusion), $\mathrm{Ru}-30$ group (30 mg/kg Ru treatment; surgery was performed in the same way as the IRI group with administration of $10 \mathrm{ml} / \mathrm{kg} \mathrm{3 \%} \mathrm{Ru}$ intraperitoneally $10 \mathrm{~min}$ prior to reperfusion), and $\mathrm{Ru}-60$ group (60 mg/kg Ru treatment; surgery was performed in the same way as the IRI group with administration of $10 \mathrm{ml} / \mathrm{kg} 6 \% \mathrm{Ru}$ intraperitoneally 10 min prior to reperfusion). Blood and kidney samples were obtained for analysis after $2 \mathrm{~h}$ and $24 \mathrm{~h}$ of reperfusion, respectively.

Measurement of serum levels of creatinine $(\mathrm{Cr})$, blood urea nitrogen (BUN) and neutrophil gelatinase-associated lipocalin (NGAL). Serum levels of $\mathrm{Cr}$ and BUN were measured on an America Johnson FS 5.1 Biochemistry analyzer (Johnson \& Johnson, New Brunswick, NJ, USA). NGAL levels were measured using an NGAL Rapid ELISA kit (cat. no. KIT 037; Neobioscience, Shenzhen, China) according to the manufacturer's instructions.

Renal histopathological assessment. The left kidney sections were stained with haematoxylin and eosin (H\&E) for the observation of renal tissues structure (BX50; Olympus Corporation, Tokyo, Japan). Renal tissues were immersed in $4 \%$ paraformaldehyde for $4 \mathrm{~h}$ and transferred to $70 \%$ ethanol. Individual lobes of renal tissues biopsy material were placed in processing cassettes, dehydrated through a serial alcohol gradient and embedded in paraffin wax blocks. Prior to staining, 5- $\mu$ m-thick renal tissue sections were dewaxed in xylene, rehydrated through decreasing concentrations of ethanol, and washed in PBS and then stained with H\&E. After staining, sections were dehydrated through increasing concentrations of ethanol and xylene. Histological assessment of tubular necrosis was measured semi-quantitatively using the method by McWhinnie et al (25). A total of 10 randomly selected high-power fields were observed per slide. Symptoms were scored from 0 to 3 according to tubular profiles involving an intersection: 0 , normal structures; 1 , tubular epithelial swelling, nuclear condensation, loss of the brush border with up to one third of the tubular profile exhibiting nuclear loss; 2, more than one-third though less than two-thirds of the tubular profile exhibiting nuclear loss; 3 , over two-thirds of the tubular profile exhibiting nuclear loss.

Measurement of NF- $\kappa B, T N F-\alpha, I L-6$ and ICAM-1 in renal tissues. Renal tissues were harvested and immediately homogenized on ice with 5 volumes of normal saline. The homogenates were centrifuged at $1,200 \mathrm{x}$ g for $10 \mathrm{~min}$ at $4^{\circ} \mathrm{C}$. NF- $\kappa \mathrm{B}, \mathrm{TNF}-\alpha$, IL- 6 and ICAM-1 levels were measured in renal tissue supernatants using commercial ELISA kits (Bioval Technologies, Shanghai, China)).

Reverse transcription-polymerase chain reaction (RT-PCR) was performed as previously described (26). Briefly, renal tissue RNA was extracted using the TRIzol reagent (Invitrogen; Thermo Fisher Scientific, Inc., Waltham, MA, USA) in accordance with the manufacturer's instructions. Any potential DNA contamination was removed by RNase-free DNaseI (cat. no. M6101, Promega Biotech Co., Ltd., Beijing, China) treatment. Then, cDNA was synthesized from the total RNA using AMV reverse transcriptase (cat. no. M5101, Promega Biotech Co., Ltd.) according to the manufacturer's instructions. The primer sequences are listed in Table I. Each 
Table I. Primer sequences for reverse transcription-polymerase chain reaction.

\begin{tabular}{|c|c|c|c|}
\hline Gene target & Primer & Sequence $\left(5^{\prime}-3^{\prime}\right)$ & Product size (bp) \\
\hline $\mathrm{NF}-\kappa \mathrm{B}$ & $\begin{array}{l}\text { Forward } \\
\text { Reverse }\end{array}$ & $\begin{array}{l}\text { GAGCCACCAATCCACACAGAGT } \\
\text { ATGAGCTTCTGGCGTTTCCTCT }\end{array}$ & 107 \\
\hline TNF- $\alpha$ & $\begin{array}{l}\text { Forward } \\
\text { Reverse }\end{array}$ & $\begin{array}{l}\text { GCAGAAGAGGCACTCCCCCA } \\
\text { GATCCATGCCGTTGGCCAGG }\end{array}$ & 326 \\
\hline IL-6 & $\begin{array}{l}\text { Forward } \\
\text { Reverse }\end{array}$ & $\begin{array}{l}\text { AGTTGCCTTCTTGGGACTGA } \\
\text { TTCTGCAAGTGCATCATCGT }\end{array}$ & 191 \\
\hline ICAM-1 & $\begin{array}{l}\text { Forward } \\
\text { Reverse }\end{array}$ & $\begin{array}{l}\text { AACCGGAAGGTGTATGAACTG } \\
\text { CGAGGTGTTCTCAAACAGCTC }\end{array}$ & 390 \\
\hline GAPDH & $\begin{array}{l}\text { Forward } \\
\text { Reverse }\end{array}$ & $\begin{array}{l}\text { AGAAGGAAATGGCTGCAGAA } \\
\text { GCTCGGCTTCCAGTATTGAG }\end{array}$ & 223 \\
\hline
\end{tabular}

NF- $\kappa$ B, nuclear factor- $\kappa$ B; TNF- $\alpha$, tumor necrosis factor- $\alpha$; IL-6, interleukin-6; ICAM-1, intercellular adhesion molecule-1 .

PCR reaction (20 $\mu \mathrm{l}$ total) contained $1 \mathrm{X}$ PCR buffer, $1.5 \mu \mathrm{M}$ of NF- $\kappa \mathrm{B}, \mathrm{TNF}-\alpha$, IL-6, ICAM-1 or $0.15 \mu \mathrm{M}$ GAPDH primers, $500 \mu \mathrm{M}$ dNTPs, $0.1 \%$ RNase-free $\mathrm{H}_{2} \mathrm{O}, 1 \mathrm{U}$ of Taq polymerase (cat. no. EP0702, Invitrogen; Thermo Fisher Scientific, Inc.) and $3 \mu \mathrm{l}$ of the cDNA template. The reaction was performed in a thermal cycler as follows: $95^{\circ} \mathrm{C}$ for 5 min then 36 cycles of $95^{\circ} \mathrm{C}$ for $1 \mathrm{~min}, 50^{\circ} \mathrm{C}$ for $1 \mathrm{~min}$ and $72^{\circ} \mathrm{C}$ for $1 \mathrm{~min}$. The amplified products were separated using $1.5 \%$ agarose gel electrophoresis, and images were obtained on a Gel Doc 2000 Imager System (Bio-Rad Laboratories, Inc., Hercules, CA, USA).

Phosphorylated ( $p)$ and total JNK and p38 MAPK western blot analyses. Endochylema and cellular nuclear proteins were extracted from frozen renal tissue with NE-PER Nuclear and Cytoplasmic Extraction reagent (cat. no. 78833, Invitrogen; Thermo Fisher Scientific, Inc.) according to the manufacturer's instructions. The total protein $(20 \mu \mathrm{g})$ were separated by $10 \%$ SDS-PAGE, transferred onto polyvinylidene fluoride membranes (EMD Millipore, Billerica, MA, USA) and then assessed by Ponceau S solution staining. The membranes were blocked with $5 \%$ dehydrated skim milk in TBS $/ 0.1 \%$ Tween 20 (TBST) for $1 \mathrm{~h}$ at room temperature and then incubated overnight at $4^{\circ} \mathrm{C}$ with primary antibodies specific to p-p38 (cat. no. SAB4301534; 1:500; Sigma-Aldrich, Merck KGaA, Darmstadt, Germany), p38 (cat. no. SAB1302631; 1:500; Sigma-Aldrich, Merck KGaA) p-JNK (cat. no. SAB4504449; 1:500; Sigma-Aldrich, Merck KGaA) and JNK (cat. no. SAB4502398; 1:500; Sigma-Aldrich, Merck KGaA). The blots were washed thrice in TBST buffer and subsequently incubated with the horseradish peroxidase-conjugated anti-rabbit secondary antibody (cat. no. A4914; 1:1000; Sigma-Aldrich, Merck KGaA) at room temperature for $1 \mathrm{~h}$ at room temperature. Specific proteins in the blots were visualized using an enhanced chemiluminescence reagent (Thermo Fisher Scientific, Inc.).

SOD and MDA assays. Renal tissues were harvested and immediately homogenized on ice with 5 volumes of normal saline. The homogenates were centrifuged at 1,200 x g for $10 \mathrm{~min}$ at $4^{\circ} \mathrm{C}$. SOD and MDA levels in the supernatant were

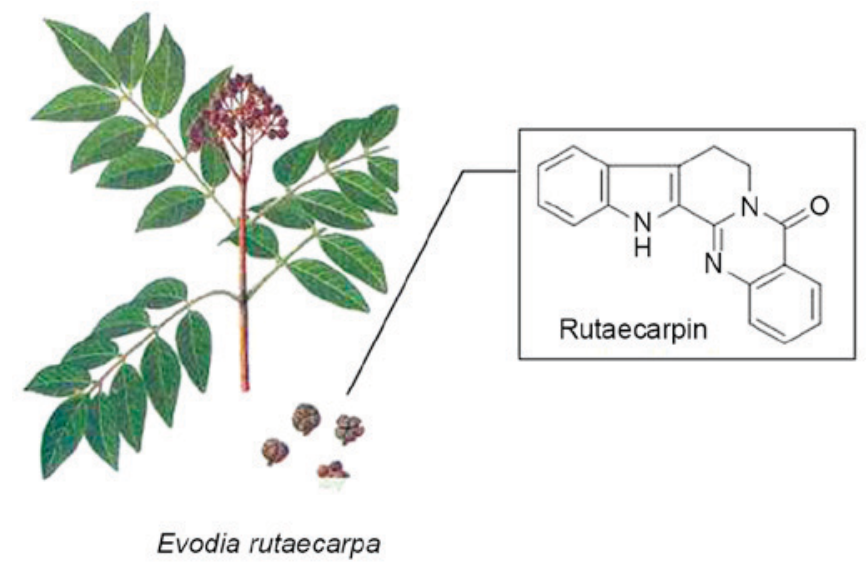

Figure 1. Evodia rutaecarpa and the structure of rutaecarpine. Adapted from Ref. 19.

determined using SOD and MDA assay kits, according to the manufacturer's instructions.

Statistical analysis. Each experiment was performed 3 times. Results are expressed as the mean \pm standard deviation. Statistical comparisons were performed using unpaired Student's t-test and one-way analysis of variance followed by Dunnett's post-hoc test. $\mathrm{P}<0.05$ was considered to indicate a statistically significant difference.

\section{Results and Discussion}

Effect of rutaecarpine on alleviating renal function injury induced by IRI. Serum Cr and BUN, which are the end products of nitrogenous organic matter and protein metabolism, serve as indicators for diagnosing and screening for glomerular filtration function (27). NGAL can reveal the occurrence of early-stage acute renal tubular injury with good sensitivity and specificity (28). As demonstrated in Table II, the levels of BUN, $\mathrm{Cr}$ and NGAL in the blood significantly increased and renal function was severely impaired in rats in the IRI and NS groups when compared with those in the sham group $(\mathrm{P}<0.05)$. 
Table II. Plasma levels of Cr, BUN, and NGAL in experimental rats.

\begin{tabular}{|c|c|c|c|c|c|}
\hline Factor & Sham & IRI & NS & $\mathrm{Ru}-30$ & $\mathrm{Ru}-60$ \\
\hline $\mathrm{Cr}(\mathrm{mmol} / \mathrm{l})$ & $37.82 \pm 2.63$ & $115.71 \pm 4.60^{\mathrm{a}}$ & $109.84 \pm 3.72^{a}$ & $77.49 \pm 3.52^{\mathrm{b}}$ & $66.72 \pm 2.14^{\mathrm{b}}$ \\
\hline BUN $(\mu \mathrm{mol} / \mathrm{l})$ & $7.94 \pm 0.62$ & $36.82 \pm 1.46^{\mathrm{a}}$ & $35.24 \pm 0.92^{\mathrm{a}}$ & $11.47 \pm 1.18^{\mathrm{b}}$ & $8.80 \pm 1.35^{\mathrm{b}}$ \\
\hline NGAL (ng/ml) & $56.38 \pm 4.57$ & $123.72 \pm 5.20^{\mathrm{a}}$ & $119.42 \pm 3.84^{\mathrm{a}}$ & $99.75 \pm 5.34^{\mathrm{b}}$ & $81.36 \pm 6.17^{b}$ \\
\hline
\end{tabular}

Data are presented as the mean \pm standard deviation ( $\mathrm{n}=10$ rats/group). ${ }^{\mathrm{a}} \mathrm{P}<0.05$ vs. sham group, ${ }^{\mathrm{b}} \mathrm{P}<0.05$ vs. IRI group. Cr, creatinine; $\mathrm{BUN}$, blood urea nitrogen; NGAL, neutrophil gelatinase-associated lipocalin; Sham, sham operation group; IRI, ischemia reperfusion injury; NS, normal saline; Ru-30, $30 \mathrm{mg} / \mathrm{kg}$ rutaecarpine treatment prior to IRI; $\mathrm{Ru}-60,60 \mathrm{mg} / \mathrm{kg}$ rutaecarpine treatment prior to IRI.
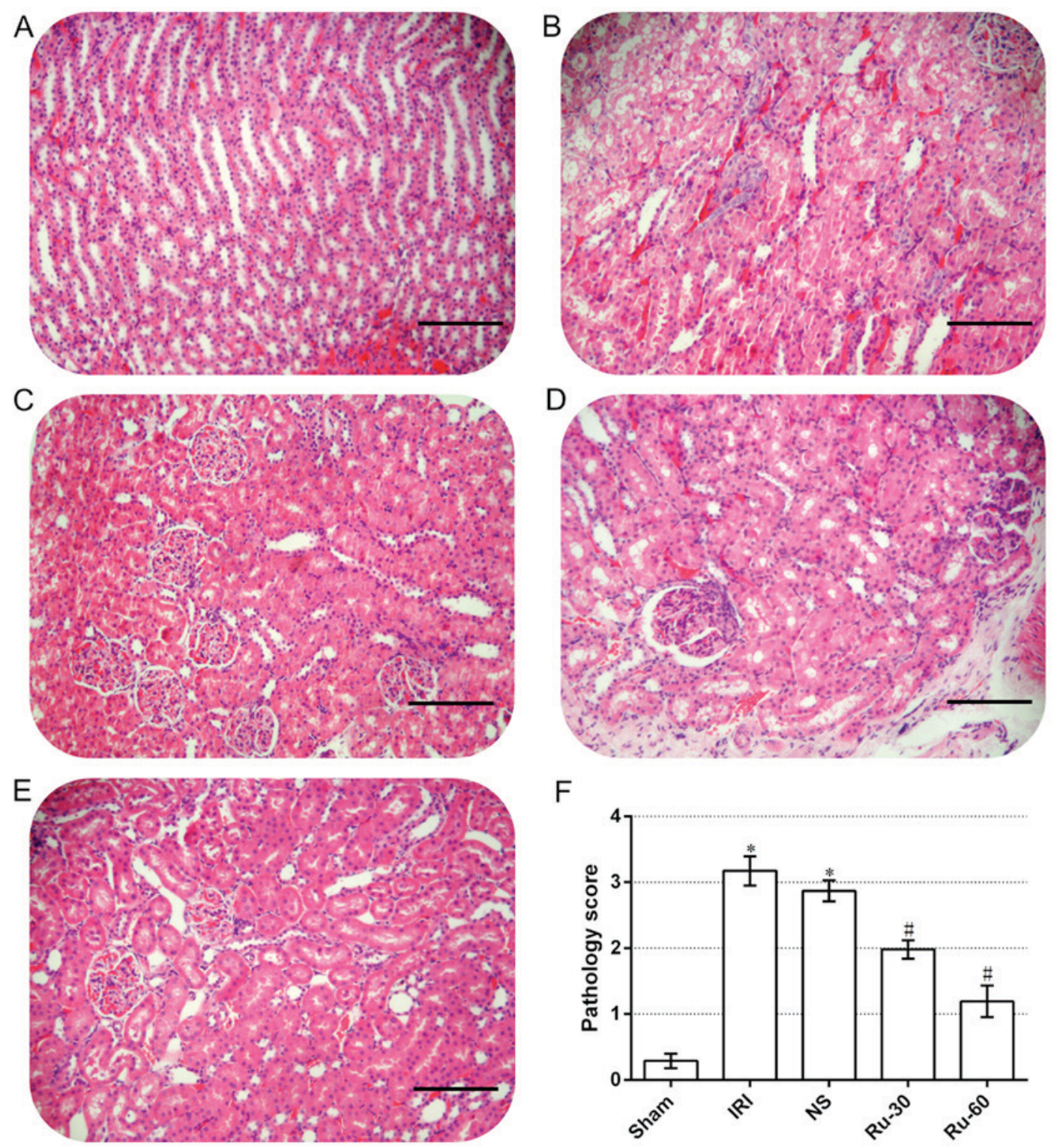

$\mathrm{F}$

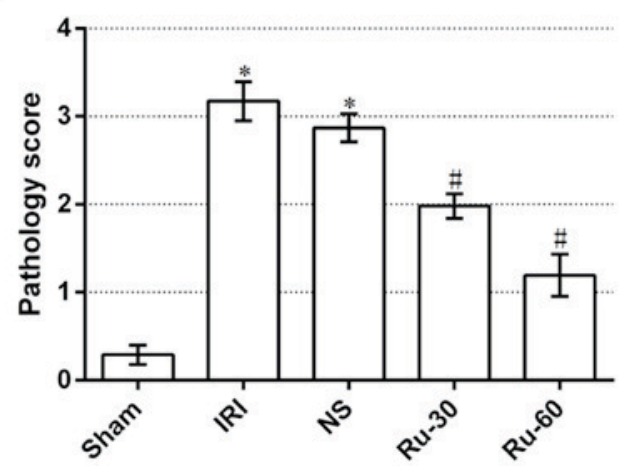

Figure 2. Effect of Ru on the degree of proximal tubules damage during renal IRI. Representative images of renal tissue sections stained with hematoxylin and eosin from rats in the (A) Sham (sham operation), (B) IRI, (C) NS, (D) Ru-30 (30 mg/kg Ru treatment prior to IRI) and (E) Ru-60 (60 mg/kg Ru treatment prior to IRI) groups. Scale bar, $200 \mu \mathrm{m}$. (F) Pathology scores. "P<0.05 vs. sham group, ${ }^{\text {"P }}<0.05$ vs. IRI group. NS, normal saline; Ru, rutaecarpine; IRI, ischemia reperfusion injury.

When compared with the IRI and NS groups, treatment with $30 \mathrm{mg} / \mathrm{kg}$ and $60 \mathrm{mg} / \mathrm{kg}$ Ru markedly decreased serum BUN, $\mathrm{Cr}$ and NAGL levels (Table II).
Rutaecarpine treatment improves the necrotic degree of proximal tubules in renal tissue. Renal tissue pathology can directly reveal the degree of renal injury induced by renal 
Table III. Comparison of NF-кB, TNF- $\alpha$, IL-6 and ICAM-1 levels in rat kidney tissues.

\begin{tabular}{lcccc}
\hline Group & NF-אB & TNF- $\alpha$ & IL-6 & ICAM-1 \\
\hline Sham & $0.57 \pm 0.13$ & $0.61 \pm 0.16$ & $1.01 \pm 1.06$ & $10.42 \pm 1.63$ \\
IRI & $1.31 \pm 0.09^{\mathrm{a}}$ & $1.18 \pm 0.14^{\mathrm{a}}$ & $6.08 \pm 1.42^{\mathrm{a}}$ & $36.54 \pm 3.16^{\mathrm{a}}$ \\
NS & $1.42 \pm 0.11^{\mathrm{a}}$ & $0.98 \pm 0.13^{\mathrm{a}}$ & $6.21 \pm 1.06^{\mathrm{a}}$ & $36.87 \pm 2.71^{\mathrm{a}}$ \\
Ru-30 & $1.02 \pm 0.21^{\mathrm{b}}$ & $0.78 \pm 0.17^{\mathrm{b}}$ & $4.91 \pm 1.37^{\mathrm{b}}$ & $30.57 \pm 3.29^{\mathrm{b}}$ \\
Ru-60 & $0.73 \pm 0.15^{\mathrm{b}}$ & $0.67 \pm 0.09^{\mathrm{b}}$ & $4.32 \pm 1.16^{\mathrm{b}}$ & $17.38 \pm 2.62^{\mathrm{b}}$ \\
\hline
\end{tabular}

Data are presented as the mean \pm standard deviation ( $\mathrm{n}=10$ rats/group). ${ }^{\mathrm{a}} \mathrm{P}<0.05$ vs. sham group, ${ }^{\mathrm{b}} \mathrm{P}<0.05$ vs. IRI group. NF- $\mathrm{kB}, \mathrm{nuclear}$ factor- $\kappa \mathrm{B}$; TNF- $\alpha$, tumor necrosis factor- $\alpha$; IL-6, interleukin-6; ICAM-1, intercellular adhesion molecule-1; Sham, sham operation group; IRI, ischemia reperfusion injury; NS, normal saline; Ru-30, $30 \mathrm{mg} / \mathrm{kg}$ rutaecarpine treatment prior to IRI; Ru- $60,60 \mathrm{mg} / \mathrm{kg}$ rutaecarpine treatment prior to IRI.

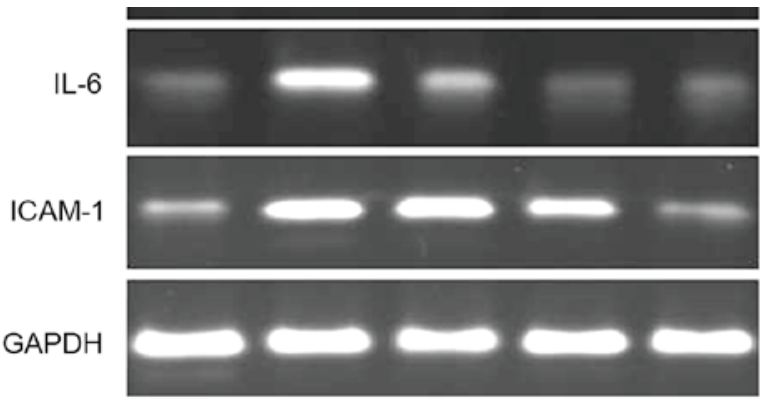

Figure 3. mRNA expression levels of NF-кB, TNF- $\alpha$, IL-6 and ICAM-1 were measured in the five experimental groups by reverse transcription-polymerase chain reaction. Representative images from the gel electrophoresis are shown, with GAPDH used as an internal reference control. NF-kB, nuclear factor- $\mathrm{kB}$; TNF- $\alpha$, tumor necrosis factor- $\alpha$; IL-6, interleukin-6; ICAM-1, intercellular adhesion molecule-1; Sham, sham operation group; IRI, ischemia reperfusion injury; NS, normal saline; Ru-30, $30 \mathrm{mg} / \mathrm{kg} \mathrm{Ru}$ treatment prior to IRI; Ru- $60,60 \mathrm{mg} / \mathrm{kg}$ Ru treatment prior to IRI.

ischemia reperfusion (29). Under a light microscope, no noticeable necrosis was observed in the renal tissue of the sham group after $24 \mathrm{~h}$ (Fig. 2A). The cellular morphology of the renal tissue from this group was normal and no vacuoles were observed in the cytoplasm (Fig. 2A). The nuclei were round or elliptical, staining was uniform and no necrotic exfoliative cells were observed in the renal tubules (Fig. 2A). Alterations in the renal tubules were similar in all experimental groups. No significant change was observed in the glomeruli. In the majority of the renal tubular epithelial cells in the IRI and NS groups, significantly swollen vacuolar degeneration and necrosis were observed (Fig. 2B and C). Karyopyknosis, karyorrhexis, cytoplasmic shrinkage, apoptotic body formation and other features of apoptosis were also observed (Fig. 2B and $\mathrm{C}$ ). The renal tubules were narrow and a large number of necrotic exfoliative cells were observed (Fig. 2B and C). Cellular and protein casts were observed in some of the renal tubules. Renal interstitial edema, congestion and inflammatory cell infiltration were also observed (Fig. 2B and C). While cellular and protein casts and apoptosis were detected in the renal tubules of the $30 \mathrm{mg} / \mathrm{kg}$ (Fig. 2D) and $60 \mathrm{mg} / \mathrm{kg}$ (Fig. 2E) $\mathrm{Ru}$ groups, edema and necrosis of renal tubular epithelial cells were significantly alleviated, and cast and leukocyte infiltration decreased.

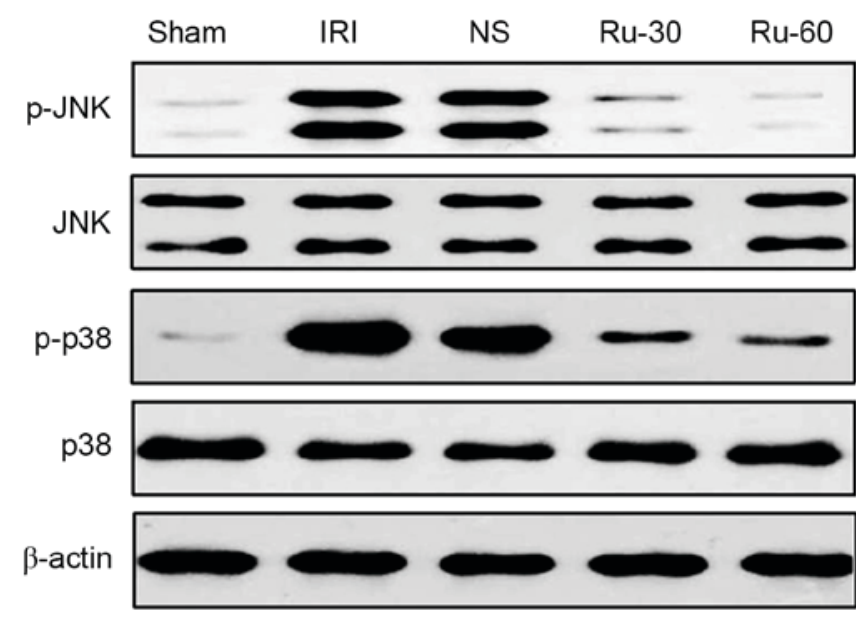

Figure 4. Effect of Ru treatment on IRI-induced p38 and JNK mitogen-activated protein kinase phosphorylation in renal tissues. Total tissue extracts were subjected to western blot analysis for protein expression levels of p-JNK, total JNK, p-p38 and total p38. $\beta$-actin was used as a loading control. $\mathrm{Ru}$, rutaecarpine; JNK, c-Jun N-terminal kinase; p, phosphorylated; Sham, sham operation group; IRI, ischemia reperfusion injury; NS, normal saline; $\mathrm{Ru}-30,30 \mathrm{mg} / \mathrm{kg}$ Ru treatment prior to IRI; Ru-60, 60 mg/kg Ru treatment prior to IRI.

The pathology scores of the sham, IRI and NS groups were $0.29 \pm 0.11,3.14 \pm 0.27$ and $2.87 \pm 0.16$, respectively (Fig. $2 \mathrm{~F}$ ). The scores for the latter groups were significantly higher than that of the sham group $(\mathrm{P}<0.05)$. The pathology scores of the $\mathrm{Ru}$ groups, $1.98 \pm 0.14$ for the Ru-30 group and $1.19 \pm 0.24$ for the Ru-60 group, were significantly lower than those of the other groups and the decrease observed was dose-dependent $(\mathrm{P}<0.05)$.

Rutaecarpine treatment inhibits the production of inflammatory cytokines in renal tissue. The inflammatory cytokines secreted by renal endothelial cells and parenchymal cells are important markers of the inflammatory response following IRI (30). As shown in Table III, when compared with the sham group, levels of the inflammatory cytokines NF- $\kappa B$, TNF- $\alpha$, IL- 6 and ICAM- 1 increased in the renal tissues of rats in the IRI, NS, Ru-30 and Ru-60 groups $(\mathrm{P}<0.05)$ compared with the sham group, indicating that inflammatory factors were released from the renal tissue during the early stage of IRI. 

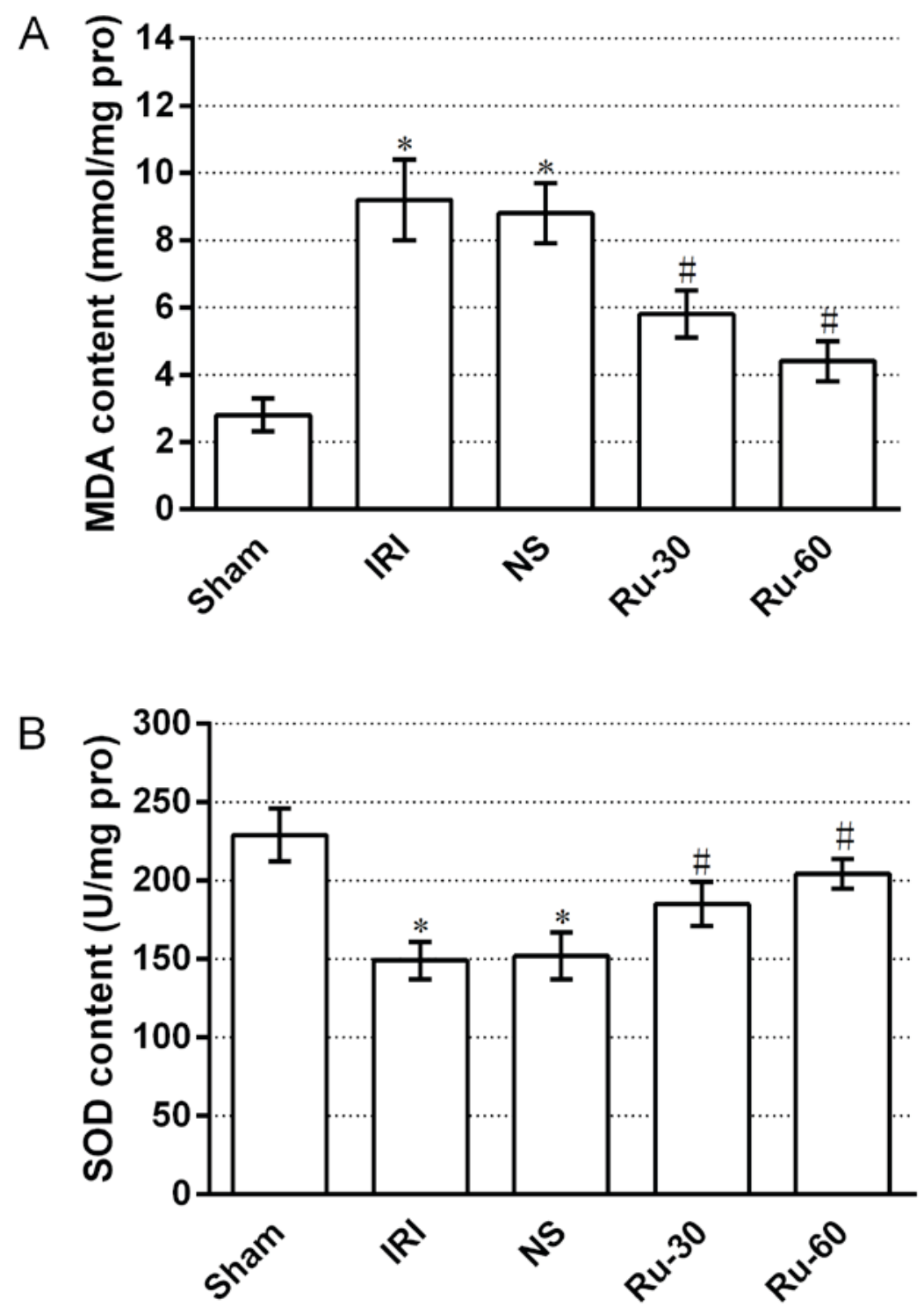

Figure 5. Changes in (A) MDA and (B) SOD content in renal tissues. ${ }^{*} \mathrm{P}<0.05$ vs. sham group; ${ }^{~} \mathrm{P}<0.05$ vs. IRI group. MDA, lipid peroxidation; SOD, superoxide dismutase activity; Sham, sham operation group; IRI, ischemia reperfusion injury; NS, normal saline; Ru, rutaecarpine; Ru-30, $30 \mathrm{mg} / \mathrm{kg}$ Ru treatment prior to IRI; Ru-60, $60 \mathrm{mg} / \mathrm{kg}$ Ru treatment prior to IRI.

When compared with the IRI group, the contents of inflammatory cytokines in the Ru-30 and Ru-60 groups decreased with increasing Ru treatment (Table III). The effect of Ru on mRNA expression levels of NF- $\kappa$ B, TNF- $\alpha$, IL-6 and ICAM-1 was also examined by RT-PCR. As demonstrated in Fig. 3, Ru treatment markedly inhibited the mRNA expression of inflammatory factors. These findings combined with the results of the renal biopsy and renal function diagnosis, indicate that $\mathrm{Ru}$ may alleviate renal injury caused by ischemia reperfusion in rats.

Rutaecarpine treatment inhibits phosphorylation of JNK and p38 in renal tissue. The MAPK signaling pathway participates in multiple cell processes, including inflammation, proliferation, differentiation and apoptosis. Activation of the MAPK signaling pathway induces the expression of cytokines, including IL-6, IL-8 and TNF- $\alpha$, which in turn enhance the inflammatory and immune responses (15-17). Therefore, the effects of Ru on the phosphorylation of JNK and p38 MAPK in renal tissue were investigated by western blotting. The experimental results are demonstrated in Fig. 4. Protein expression levels of p-JNK and p-p38 MAPK in the renal tissues from rats treated with different concentrations (30 or $60 \mathrm{mg} / \mathrm{kg}$ ) of Ru were lower than those in the sham and NS groups. Among the groups tested, the decrease in p-JNK and p-p38 MAPK was obvious in the Ru-60 treated group. Total levels of p38 and JNK MAPKs were not affected by IRI or by IRI in combination with Ru. These results suggest that Ru treatment effectively suppressed IRI-induced phosphorylation of JNK and p38MAPK, which may be involved in reducing cellular damage in renal tissue following IRI. 
Rutaecarpine treatment significantly decreases MDA contents and increases SOD activity in renal tissue. The oxidative stress response is an important indicator of the early stage of renal tissue injury following IRI (31). MDA, a degradation product of lipid peroxidation, can disturb protein, glucose and nucleic acid metabolism, decrease enzyme activity, induce nucleic acid template dysfunction and tissue structure damage, and exacerbate IRI (32). Thus, MDA levels reflect the content of ROS in cells. SOD is a major macromolecule antioxidant that eliminates ROS in vivo and can disproportionate oxygen into hydrogen peroxide to protect cells from ROS damage. SOD activity thus represents the ability of an organ to eliminate ROS (33). Consistent with the observed changes in renal function, the MDA contents (Fig. 5A) increased and SOD activity (Fig. 5B) decreased in renal tissue following IRI, compared with the sham group. These alterations were consistent with the deterioration of renal function, indicating that renal IRI induced renal ROS production, increased endogenous antioxidant consumption, significantly decreased the ability of cells to eliminate ROS and exacerbated renal damage. Ru treatment $10 \mathrm{~min}$ prior to ischemia markedly reduced MDA contents and enhanced SOD activity in renal tissues, compared with the IRI group. Thus, Ru treatment may have increased ROS scavenging by decreasing ROS generation and inhibiting lipid peroxidation to relieve renal damage.

The present study confirmed that rutaecarpine exerted extensive anti-IRI effects. Ru treatment was demonstrated to block activation of the JNK/p38 MAPK signaling pathway, inhibit transcription of inflammatory cytokines, resist lipid peroxidation and eliminate free radicals, all of which may help to alleviate renal ischemia reperfusion-induced apoptosis and oxidative stress injury. Therefore, rutaecarpine may be an effective compound to prevent or treat renal IRI.

\section{Acknowledgements}

The present study was supported by the National Natural Science Foundation of China (grant nos. 81370856 and 81272092).

\section{References}

1. Wasser WG, Krakoff LR, Haimov M, Glabman S and Mitty HA: Restoration of renal function after bilateral renal artery occlusion. Arch Intern Med 141: 1647-1651, 1981.

2. Devarajan P: Update on mechanisms of ischemic acute kidney injury. J Am Soc Nephrol 17: 1503-1520, 2006.

3. Sharfuddin AA and Molitoris BA: Pathophysiology of ischemic acute kidney injury. Nat Rev Nephrol 7: 189-200, 2011.

4. Ali T, Khan I, Simpson W, Prescott G, Townend J, Smith W and Macleod A: Incidence and outcomes in acute kidney injury: A comprehensive population-based study. J Am Soc Nephrol 18: 1292-1298, 2007.

5. Lenaerts K, Ceulemans LJ, Hundscheid IH, Grootjans J, Dejong $\mathrm{CH}$ and Olde Damink SW: New insights in intestinal ischemia-reperfusion injury: Implications for intestinal transplantation. Curr Opin Organ Transplant 18: 298-303, 2013.

6. Salvadori M, Rosso G and Bertoni E: Update on ischemia-reperfusion injury in kidney transplantation: Pathogenesis and treatment. World J Transplant 5: 52-67, 2015.

7. Menke J, Sollinger D, Schamberger B, Heemann U and Lutz J: The effect of ischemia/reperfusion on the kidney graft. Curr Opin Organ Transplant 19: 395-400, 2014.

8. Friedewald JJ and Rabb H: Inflammatory cells in ischemic acute renal failure. Kidney Int 66: 486-491, 2004.

9. Ysebaert DK, De Greef KE, De Beuf A, Van Rompay AR, Vercauteren S, Persy VP and De Broe ME: T cells as mediators in renal ischemia/reperfusion injury. Kidney Int 66: 491-496, 2004.
10. Thurman JM: Triggers of inflammation after renal ischemia/reperfusion. Clin. Immunol 123: 7-13, 2007.

11. Garcia-Criado FJ, Eleno N, Santos-Benito F, Valdunciel JJ, Reverte M, Lozano-Sánchez FS, Ludeña MD, Gomez-Alonso A and López-Novoa JM: Protective effect of exogenous nitric oxide on the renal function and inflammatory response in a model of ischemia-reperfusion. Transplantation 66: 982-990, 1998.

12. Shingu C, Koga H, Hagiwara S, Matsumoto S, Goto K, Yokoi I and Noguchi T: Hydrogen-rich saline solution attenuates renal ischemia-reperfusion injury. J Anesth 24: 569-574, 2010.

13. Wang F, Yu G, Liu SY, Li JB, Wang JF, Bo LL, Qian LR, Sun XJ and Deng XM: Hydrogen-rich saline protects against renal ischemia/reperfusion injury in rats. J Surg Res 167: e339-e344, 2011.

14. Pearson G, Robinson F, Beers Gibson T, Xu BE, Karandikar M, Berman K and Cobb MH: Mitogen-activated protein (MAP) kinase pathways: Regulation and physiological functions. Endocr Rev 22: 153-183, 2001

15. Terada Y, Inoshita S, Kuwana H, Kobayashi T, Okado T, Ichijo H and Sasaki S: Important role of apoptosis signal-regulating kinase 1 in ischemic acute kidney injury. Biochem Biophys Res Commun 364: 1043-1049, 2007.

16. El-Mas MM, El-Gowelli HM, Ghazal AR, Harraz OF and Mohy El-Din MM: Facilitation of central imidazoline I(1)-site/extracellular signal-regulated kinase/p38 mitogen-activated protein kinase signalling mediates the hypotensive effect of ethanol in rats with acute renal failure. Br J Pharmacol 158: 1629-1640, 2009.

17. Irving EA and Bamford $\mathrm{M}$ : Role of mitogen- and stress-activated kinases in ischemic injury. J Cereb Blood Flow Metab 22: 631-647, 2002.

18. Kaminska B: MAPK signalling pathways as molecular targets for anti-inflammatory therapy-from molecular mechanisms to therapeutic benefits. Biochim Biophys Acta 1754: 253-262, 2005.

19. Guining Wei (ed): Evodia rutaecarpa. In: Shen Nong's Herbal Classic. Military Medical Science Press, Beijing, pp90, 2015.

20. Hou X, Yu Z, Xu Z, Wang Y and Dai F: Determination of the Contents of Evodiamine and Rutaecarpine in 34 Species of Evodia Rutaecarpa by HPLC. J Shenyang Pharm Univ 17: 334-337, 2000.

21. Yu Q, Guo C and Cheng Z: Current advances in the study on rutaecarpine. Yaoxue Shijian Zazhi 25: 353-357, 2007.

22. $\mathrm{Hu} \mathrm{CP}$ and $\mathrm{Li}$ YJ: Research progress in pharmacological actions of evodiamine and rutaecarpine. Zhongguo Yaolixue Tongbao 19: 1084-1087, 2003.

23. Lee SH, Son JK, Jeong BS, Jeong TC, Chang HW, Lee ES and Jahng Y: Progress in the studies on rutaecarpine. Molecules 13: 272-300, 2008.

24. Mutlu G, Abbasoğlu L, Doğru-Abbasoğlu S, Solakoğlu S and Bulut M: Morphologic changes and lipid peroxidation in renal tissues of young rats following intestinal ischemia-reperfusion. Pediatr Surg Int 18: 337-340, 2002.

25. McWhinnie DL, Thompson JF, Taylor HM, Chapman JR, Bolton EM, Carter NP, Wood RF and Morris PJ: Morphometric analysis of cellular infiltration assessed by monoclonal antibody labeling in sequential human renal allograft biopsies. Transplantation 42: 352-358, 1986.

26. Yang S, Chou WP and Pei L: Effects of propofol on renal ischemia/reperfusion injury in rats. Exp Ther Med 6: 1177-1183, 2013.

27. Trof RJ, Di Maggio F, Leemreis J and Groeneveld AB: Biomarkers of acute renal injury and renal failure. Shock 26: 245-253, 2006.

28. Di Grande A, Giuffrida C, Carpinteri G, Narbone G, Pirrone G, Di Mauro A, Calandra S, Noto P, Le Moli C, Alongi B and Nigro F: Neutrophil gelatinase-associated lipocalin: A novel biomarker for the early diagnosis of acute kidney injury in the emergency department. Eur Rev Med Pharmacol Sci 13: 197-200, 2009.

29. Makris K and Spanou L: Acute kidney injury: Definition, pathophysiology and clinical phenotypes. Clin Biochem Rev 37: 85-98, 2016.

30. Oguz E, Yilmaz Z, Ozbilge H, Baba F, Tabur S, Yerer MB and Hekimoglu A: Effects of melatonin on the serum levels of pro-inflammatory cytokines and tissue injury after renal ischemia reperfusion in rats. Ren Fail 37: 318-322, 2015.

31. McCullough JW, Renner B and Thurman JM: The role of the complement system in acute kidney injury. Semin Nephrol 33: 543-556, 2013.

32. Gutteridge JM and Halliwell B: The measurement and mechanism of lipid peroxidation in biological systems. Trends Biochem Sci 15: 129-135, 1990 .

33. Tábara LC, Poveda J, Martin-Cleary C, Selgas R, Ortiz A and Sanchez-Niño MD: Mitochondria-targeted therapies for acute kidney injury. Expert Rev Mol Med 16: e13, 2014. 